\title{
Molecular analysis of the androgen receptor gene in testicular cancer
}

\author{
A Garolla, A Ferlin, C Vinanzi, A Roverato ${ }^{1}$, G Sotti $^{2}$, W Artibani $^{3}$ \\ and C Foresta
}

University of Padua, Department of Histology, Microbiology and Medical Biotechnologies, Centre for Male Gamete
Cryopreservation, Padua, Italy
${ }^{1}$ University of Modena and Reggio Emilia, Department of Social, Cognitive and Quantitative Sciences, Modena, Italy
${ }^{2}$ University of Padua, Department of Radiotherapy and Nuclear Medicine, Padua, Italy
${ }^{3}$ University of Padua, Department of Oncological and Surgical Sciences, Padua, Italy

(Requests for offprints should be addressed to C Foresta; Email: carlo.foresta@unipd.it)

\begin{abstract}
Testicular cancer (TC) is the most common solid tumour in white males aged 20-34 years, and its incidence has doubled over the past 40 years. Some risk factors for TC have been proposed, such as cryptorchidism, infertility and testicular dysgenesis. However, the causes of TC remain still largely unknown. Recently a genetic basis for TC has been proposed, but specific genetic alterations have not been identified. The risk of TC is markedly increased in subjects with androgen insensitivity and some authors have suggested that mutations in the androgen receptor (AR) gene or disorders of CAG and GGC repeats could be related to TC. However, definitive data have not been produced. In this study, we analysed the AR gene for mutations and CAG and GGC triplets in exon 1 in 123 patients affected by TC. In three patients (2.3\%) we found a mutation in the AR gene, two of which represent a novel mutation. Evaluation of CAG and GGC repeat numbers showed no difference with respect to controls when these variables were analysed separately. However, when joint distributions of CAG and GGC were considered, we found that the combination CAG $=20$ / $\mathrm{GGC}=17$ was significantly more frequent in TC patients $(8.1 \%)$ with respect to controls $(1.7 \%$, $P<0.05)$. Furthermore, we observed that in TC subjects, differently from controls, the joint analysis of $C A G$ and $G G C$ showed a statistically significant dependence among these variable repeats. In conclusion, our data show for the first time a high prevalence of AR gene mutations in patients affected by TC and suggest that some CAG/GGC combinations might be more frequently associated with an increased risk of TC.
\end{abstract}

Endocrine-Related Cancer (2005) 12 645-655

\section{Introduction}

Testicular cancer (TC) is the most common solid tumour in white males between 20 and 34 years (Møller 1993, Huyghe et al. 2003, Patel et al. 2003). About 95\% of all TCs are represented by germ cell tumours (GCTs) and seminoma accounts for approximately $50 \%$ of all GCTs (Bosl \& Motzer 1997). The incidence of TC varies according to geographical area, with a major incidence in the north of Europe and New Zealand (Adami et al. 1994, Bosl \& Motzer 1997, Toppari et al. 2002, Hemminki \& Li 2004). The worldwide incidence of TC has more than doubled over the past 40 years (Devesa 1995, Bosl et al. 1997, Huyge et al. 2004).
Some risk factors for TC have been proposed, but the causes of TC remain still largely unknown. To date, other than cryptorchidism, few risk factors have been clearly demonstrated for TC (Chilvers et al. 1986, Giwercman 1992). About $7-10 \%$ of patients, who develop TC, report a history of undescended testis (Shottenfeld et al. 1980, Farrer et al. 1985, Whitaker 1988), with an increased relative risk of TC for excryptorchid men. Interestingly, this risk is not confined to the cryptorchid testis but also to the contralateral normally descended testis (Berthelsen et al. 1982, Pottern et al. 1985).

Recently, an association between TC and male infertility has been proposed (Berthelsen \& Skakkebæk 1983, Giwercman et al. 1989, Prener et al. 1996, Arai 
et al. 1997, Herr et al. 1998, Jacobsen et al. 2000, Rørth et al. 2000) and common aetiological factors have been suggested. Increasing adverse factors in male reproductive health as reduced sperm quality, TC, undescended testis and hypospadias might be symptoms of one underlying entity named testicular dysgenesis syndrome (TDS) (Møller \& Skakkebæk 1999, Skakkebæk et al. 2001, 2003, Aitken \& Sawyer 2003, Bolsen et al. 2004). The aetiology of TDS is supposed to be related either to environmental factors, so-called endocrine disrupters (Weir et al. 2000, Huyge et al. 2004), and chemical toxicants (Toppari \& Skakkebæk 1998, Guo et al. 2000) or to genetic factors (Rapley et al. 2000, Hemminki \& Li 2004), including genetic susceptibility to endocrine disruption (Skakkebæk et al. 2003). TDS is supposed to arise during early foetal development when male reproductive tract formation, germ cell proliferation and Sertoli and Leydig cell differentiation occur (Yasuda et al. 1985, Sharpe \& Skakkebæk 1993, Skakkebæk et al. 2001). According to this hypothesis, different degrees of TDS would be possible, the most severe cases including all the components, i.e. hypospadias, undescended testis, TC and spermatogenic impairment.

Anomalies in the androgen receptor (AR) gene could theoretically be a good candidate responsible for TDS. In fact, mutations in the AR gene cause different forms of androgen insensitivity leading to variable malformations, including micropenis, hypospadia, cryptorchidism and spermatogenic impairment (Brinkmann 2001, Sultan et al. 2001). Furthermore, this gene is essential for the development and maintenance of the male phenotype and spermatogenesis, and the androgen insensitivity syndrome (AIS) is a well recognized risk factor for TC (Savage \& Lowe 1990). However, androgen insensitivity signs and mutations in the AR gene are not frequently reported in patients affected by TC.

The AR gene has two polymorphic sites in exon 1, characterized by different numbers of CAG and GGC repeats resulting in variable lengths of polyglutamine and polyglycine stretches in the $\mathrm{N}$-terminal region of the AR protein. Longer CAG repeats result in a reduced AR transcriptional activity (Chamberlain et al. 1994, Choong et al. 1996), and there is evidence that an inverse correlation between CAG number and androgenicity exists. In fact, expansion of the CAG repeat tract to $>40$ results in Kennedy syndrome, a rare motor neuron disorder which is also characterized by low masculinization, testicular atrophy, reduced sperm production and infertility (Brooks \& Fischbeck 1995, Kazemi-Esfarjani et al. 1995). On the other hand, shorter AR polyglutamine tracts have been associated with increased prostate cancer risk (Giovannucci et al. 1997, Hakimi et al. 1997, Ingles et al. 1997, Stanford et al. 1997, Kantoff et al. 1998, Platz et al. 1998, Hsing et al. 2000, Ding et al. 2004), but this is still a controversial matter. Epidemiological studies suggest that CAG length may also play a role in TC. AfroAmericans have shorter CAG repeats than Caucasians (Irvine et al. 1994, Kittles et al. 2001, Lundin et al. 2003), and this trend parallels the low risk of TC in the former group (Shottenfeld et al. 1980). However, only two reports have analysed the possible association between CAG length and TC, with contrasting data (Rajpert-De Meyts et al. 2002, Giwercman et al. 2004). Furthermore, the functional consequences of variations in the GGC repeats are even less clear, and the joint distribution of CAG and GGC lengths in TC has never been analysed. This is particularly important because in a previous study (Ferlin et al. 2004a), we found that some combinations of CAG and GGC triplets were significantly associated with an increased risk of spermatogenic impairment.

To clarify these aspects, in this study, we analysed AR gene mutations and $\mathrm{CAG}$ and GGC repeats in men affected by different types of TC, and who consulted our Centre for semen cryopreservation after orchiectomy and before chemotherapy or radiotherapy.

\section{Materials and methods}

\section{Subjects}

Patients and controls were prospectively recruited for this study with the approval of the Hospital Ethical Committee and informed consent was obtained from each subject after full explanation of the purpose and nature of all procedures used.

We evaluated 123 consecutive subjects (mean age $29.3 \pm 7.1$ years) orchiectomized for TC, who consulted our Centre for sperm cryobanking before initiating chemo- or radiotheraphy. All patients had a tumour in stage I at the time of our evaluation. A complete medical history and physical examination were undertaken. Two patients affected by seminoma had a familial history of TC. In the first the father and in the latter case a brother had a positive history of seminoma. Karyotype analysis and $\mathrm{Y}$ chromosome microdeletion analysis (Foresta et al. 1997, Ferlin et al. $2003,2004 b$ ) were performed in all subjects to exclude other potential causes of testicular damage.

Among 300 fertile controls analysed for AR mutations we selected as controls 115 age-matched $(28.8 \pm 6.3)$ men who also had the determination of CAG and GGC repeats performed. These subjects 
were chosen on the basis of normozoospermia (World Health Organisation 1999) and absence of previous or familiar history of TC and served as controls. All patients and controls were of Caucasian origin and came from different Italian regions.

\section{AR gene mutation analysis and determination of the CAG and GGC repeat number}

AR gene mutation analysis and determination of the CAG and GGC repeat number were performed as previously described (Ferlin et al. 2004a). Genomic DNA was extracted from peripheral blood leukocytes using a DNA isolation kit (Roche). AR gene mutations were evaluated by PCR and direct sequencing, using a set of 11 oligonucleotide primers covering exons 1-8 (Lubahn et al. 1989). DNA samples isolated from testicular tumours to perform somatic AR mutation analyses were not available.

The number of CAG and GGC triplets was determined as follows: the AR exon 1 was amplified from genomic DNA in two different PCR reactions, giving overlapping amplicons. Both reactions are performed under the same conditions (standard conditions with $8 \%$ dimethylsulphoxide) and with the same cycle $\left(94^{\circ} \mathrm{C}\right.$ for $1 \mathrm{~min}, 58^{\circ}$ for $1 \mathrm{~min}, 72^{\circ} \mathrm{C}$ for $1 \mathrm{~min}$, repeated 37 times). The $\mathrm{CAG}$ repeat is contained in the amplicon produced with primers A0 GTGGTTGCTCCCGCAAGTTTCC and A5 GCTCCCACTTCCTCCAAGGACAATTA. It is sequenced with the primer A2 GCTGTGAAGGTTGCTGTTCCTC, using standard conditions for automated sequencing. The GGC repeat is amplified with primers A3n CAGCAAGAGACTAGCCCCAG and A10 CCAGAACACAGAGTGACTCTGCC, and it is sequenced with primer A8 GGACTGGGATAGGGCACTCTGCTCAACC. Primers A2, A5, A8 and A10 are from Lubahn et al. (1989), whereas we designed the new primers A0 and A3n (Ferlin et al. 2004a). Sequence analyses were performed by using the gap4 software of the Staden package (Staden 1996) available at the UK Human Genome Mapping Project webpage (http://hgmp. mrc.ac.uk/).

\section{Statistical analysis}

Differences in CAG and GGC mean repeat length among groups were tested by the Wilcoxon's rank sum test. Differences among frequencies were calculated with a $\chi^{2}$-test and Fisher's exact test. Fisher's exact test was used to analyse independence in the three two-way contingency tables. Adjusted residuals for the different haplotypes were computed to investigate in which way they depart from independence and differ from those of the control group. Relative risks and the corresponding 95\% confidence intervals were calculated on the basis of the asymptotic normal distribution of these quantities. $P<0.05$ was considered statistically significant. A Bonferroni test was performed to correct for multiple comparisons. Computations were performed by using the open-source statistical software 'R'.

\section{Results}

None of the patients had clinical features, by history or clinical evaluation, of androgen resistance or neurological symptoms.

All 123 patients had a stage I TC and Table 1 reports their histotypes. Of the 123 , totally $18(14.6 \%)$ were excryptorchid subjects, and Table 2 reports the different histotypes and the side of TC and cryptorchidism in these patients. No other significant pathologies were found at history and physical examination.

Karyotype and Y chromosome microdeletion analysis were normal in all subjects.

Three out of 123 patients $(2.4 \%)$ had mutations in the AR gene. One of them is an already reported mutation (www.androgendb.mcgill.ca) caused by a C to $\mathrm{T}$ transition in exon 1 leading to a proline to serine substitution in amino acid 390 (P390S). The same mutation was previously reported in two men affected by mild AIS with severe oligozoospermia. The other two are novel mutations. One is a trinucleotide deletion (CTG) in exon 1 leading to deletion of leucine in position 57 (Del L57), whereas the other is a $\mathrm{G}$ to $\mathrm{A}$ transition in exon 1 leading to an alanine to threonine substitution in amino acid 297 (A297T). All three patients had seminoma and did not have a history of cryptorchidism. None of 300 fertile subjects

Table 1 Histotypes observed in 123 subjects affected by TC

\begin{tabular}{lc}
\hline Germ cell tumours & $116(94.3 \%)$ \\
Seminoma & $81(65.9 \%)$ \\
Teratoma & $9(7.3 \%)$ \\
Embryonal carcinoma & $8(6.5 \%)$ \\
Yolk sac & $3(2.4 \%)$ \\
Chorioncarcinoma & $2(1.6 \%)$ \\
Mixed germ cells & $13(10.6 \%)$ \\
Non-germ cell tumours & $7(5.7 \%)$ \\
Leydig cells & $4(3.3 \%)$ \\
Lymphoma & $2(1.6 \%)$ \\
Gonadoblastoma & $2(0.8 \%)$ \\
\hline
\end{tabular}


Table 2 Cryptorchid side, cancer side and histotypes observed in 18 ex-cryptorchid TC patients

\begin{tabular}{rlll}
\hline Patient & $\begin{array}{c}\text { Cryptorchid } \\
\text { side }\end{array}$ & $\begin{array}{c}\text { Cancer } \\
\text { side }\end{array}$ & Histotype \\
\hline 1 & Bilateral & Right & Seminoma \\
2 & Left & Left & Seminoma \\
3 & Bilateral & Bilateral & Seminoma/seminoma \\
4 & Left & Right & Embryonal carcinoma \\
5 & Left & Left & Seminoma \\
6 & Right & Right & Seminoma \\
7 & Right & Right & Leydig cells \\
8 & Left & Left & Seminoma \\
9 & Left & Left & Embryonal carcinoma \\
10 & Bilateral & Bilateral & Seminoma/teratoma \\
11 & Left & Left & Teratoma \\
12 & Right & Right & Seminoma \\
13 & Bilateral & Right & Seminoma \\
14 & Right & Right & Seminoma \\
15 & Right & Right & Seminoma \\
16 & Bilateral & Left & Seminoma \\
17 & Bilateral & Right & Teratoma \\
18 & Left & Left & Embryonal carcinoma \\
\hline
\end{tabular}

including our control group (115 subjects) had AR mutations.

Table 3 shows the mean number of CAG and GGC repeats in exon 1 of the AR gene in TC patients $(22.3 \pm 3.4$, range $11-31$ and $17.2 \pm 1.4$, range $10-20$ respectively) and in proven fertile control men (21.6 \pm 3.3 , range 9-31 and $17.0 \pm 1.7$, range 8-21). These differences were not statistically significant. There was also no difference when the median value of CAG and GGC numbers were compared. The subgrouping of TC patients by a positive or negative previous history of cryptorchidism also showed no differences in terms of mean and median values of CAG and GGC repeat number with respect to controls (Table 3). The distribution of CAG (Fig. 1a) and GGC (Fig. 1b) allele frequencies was not different between TC patients and control subjects. To explore the possibility that AR sensitivity could be determined by the total number of CAG and GGC repeats, we calculated the sum of triplets in each subject
$(\mathrm{CAG}+\mathrm{GGC})$. This number was not different between controls and patients (data not shown). We also analysed whether TC men may have longer CAG repeats (Giwercman et al. 2004) by comparing the proportion of men with $>23,>24,>25,>26$ and $>27$ repeats. In this case, we also found no differences between patients and controls as well as between the different TC histotypes (data not shown). The same analysis was performed for GGC repeats $(>18,>19$ and $>20$ ) and no difference was found (data not shown). All these analyses to find a possible correlation of TC with either CAG and GGC repeats were also performed distinguishing GCTs and non-GCTs. This partition did not allow us to discern any statistically significant difference among the two groups, but these data cannot be conclusive because of the small number of the latter group.

Then we considered the joint distribution of CAG and GGC. For this analysis the data were collected in two-way tables (Tables 4-6) reporting frequencies for each CAG/GGC haplotype. As a first step we analysed the association of the two variables. This analysis was performed by applying Fisher's exact test for independence in the three two-way tables corresponding to the 115 control $(P=0.3)$ (Table 4$), 123$ TC $(P=0.01)$ (Table 5) and 105 non-cryptorchid TC $(P=0.01)$ (Table 6) patients respectively. This finding highlights a difference between control and TC patients both with and without cryptorchidism. More specifically, in the former group the hypothesis of dependence between CAG and GGC is rejectable, whereas in the latter groups this hypothesis is statistically significant. Consequently, it is of interest to investigate in which way the data for the TC groups depart from independence, because this will also indicate in which way the behaviour of pathological patients differs from that of the control group. We have thus computed the adjusted residual for every cell of Tables 4-6 (Agresti \& Finlay 1997). For every cell, the adjusted residual is positive when the observed frequency exceeds the value expected under independence, and negative otherwise. Furthermore, under independence every adjusted

Table 3 CAG and GGC values in TC patients and controls

\begin{tabular}{|c|c|c|c|c|c|c|c|c|}
\hline & \multicolumn{4}{|c|}{ CAG } & \multicolumn{4}{|c|}{ GGC } \\
\hline & No. of alleles & Range & Mean \pm S.D. & Median & No. of alleles & Range & Mean \pm S.D. & Median \\
\hline Controls $(n=115)$ & 17 & $9-31$ & $21.6 \pm 3.3$ & 22 & 10 & $8-21$ & $17.0 \pm 1.7$ & 17 \\
\hline All TC patients $(n=123)$ & 16 & $11-31$ & $22.3 \pm 3.4$ & 23 & 8 & $10-20$ & $17.2 \pm 1.4$ & 17 \\
\hline TC no cryptorchidism $(n=105)$ & 16 & $11-31$ & $22.2 \pm 3.5$ & 22 & 8 & $10-20$ & $17.3+1.5$ & 17 \\
\hline TC + cryptorchidism $(n=18)$ & 8 & $19-27$ & $23.0 \pm 2.4$ & 23 & 4 & $12-18$ & $16.9+1.4$ & 17 \\
\hline
\end{tabular}

No statistically significant $(P<0.05)$ differences were observed. 

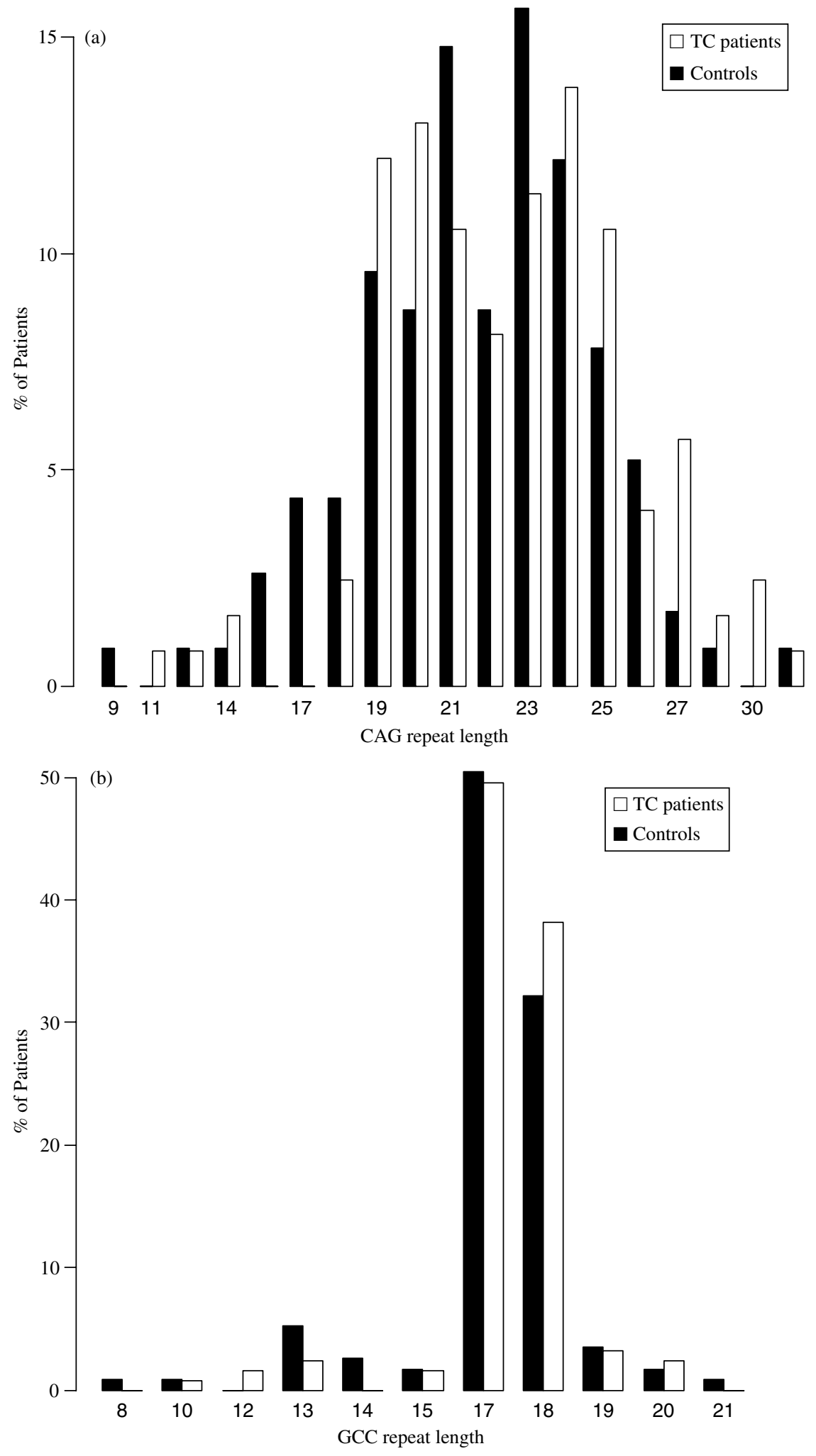

Figure 1 (a) Distribution of CAG allele frequencies observed in TC patients and control subjects. It is possible to see that there is no difference among patients and controls. (b) Distribution of GGC allele frequencies observed in TC patients and control subjects. It is possible to see that there is no difference among patients and controls. 
Table 4 Joint distribution of CAG and GGC percentages (number in round bracket and adjusted residuals in square bracket parenthesis) for the 115 fertile control men

\begin{tabular}{|c|c|c|c|c|c|}
\hline \multirow[b]{2}{*}{ CAG } & \multicolumn{5}{|c|}{ GGC } \\
\hline & $\leq 16$ & 17 & 18 & $\geq 19$ & Total \\
\hline$\leq 19$ & $1.7(2)[-0.7]$ & $9.6(11)[-1.1]$ & 10.4 (12) [1.5] & 1.7 (2) [0.3] & $23.4(27)$ \\
\hline 20 & 1.7 (2) [0.9] & $1.7(2)[-2.0]$ & $4.4(5)[1.2]$ & 0.9 (1) [0.5] & 8.7 (10) \\
\hline 21 & 0.9 (1) $[-0.7]$ & $7.0(8)[-0.3]$ & $5.2(6)[0.3]$ & 1.7 (2) [1.0] & $14.8(17)$ \\
\hline 22 & $0.0(0)[-1.1]$ & $5.2(6)[0.6]$ & 3.5 (4) [0.5] & $0.0(0)[-0.8]$ & 8.7 (10) \\
\hline 23 & $1.7(2)[-0.1]$ & 12.2 (14) [2.5] & 1.7 (2) $[-2.0]$ & $0.0(0)[-1.1]$ & $15.6(18)$ \\
\hline 24 & 0.9 (1) $[-0.5]$ & $6.1(7)[-0.1]$ & $4.4(5)[0.3]$ & 0.9 (1) $[0.1]$ & $12.3(14)$ \\
\hline 25 & $1.7(2)[1.0]$ & $3.5(4)[-0.3]$ & $1.7(2)[-0.6]$ & 0.9 (1) [0.6] & $7.8(9)$ \\
\hline$\geq 26$ & 2.6 (3) [1.9] & $5.2(6)[0.6]$ & $0.9(1)[-1.5]$ & $0.0(0)[-0.8]$ & $8.7(10)$ \\
\hline Total & $11.2(13)$ & $50.5(58)$ & $32.2(37)$ & $6.1(7)$ & 100.0 \\
\hline
\end{tabular}

$P$ values with respect to that found in TC patients with and without cryptorchidism are reported in Table 7.

Table 5 Joint distribution of CAG and GGC percentages (number in round bracket and adjusted residuals in square bracket parenthesis) for the $123 \mathrm{TC}$ patients

\begin{tabular}{|c|c|c|c|c|c|}
\hline \multirow[b]{2}{*}{ CAG } & \multicolumn{5}{|c|}{ GGC } \\
\hline & $\leq 16$ & 17 & 18 & $\geq 19$ & Total \\
\hline$\leq 19$ & $0.8(1)[-0.4]$ & $2.4(3)[-3.7]$ & $13.9(17)[4.1]$ & $0.8(1)[-0.2]$ & $17.9(22)$ \\
\hline 20 & $0.0(0)[-1.1]$ & $8.1(10)[1.1]$ & $4.9(6)[-0.1]$ & $0.0(0)[-1.0]$ & $13.0(16)$ \\
\hline 21 & $0.8(1)[0.2]$ & $5.8(7)[0.3]$ & $4.1(5)[0.1]$ & $0.0(0)[-0.9]$ & $10.7(13)$ \\
\hline 22 & $0.8(1)[0.5]$ & 4.9 (6) [0.7] & $2.4(3)[-0.5]$ & $0.0(0)[-0.8]$ & $8.1(10)$ \\
\hline 23 & $0.0(0)[-1.0]$ & 7.3 (9) [1.2] & $2.4(3)[-1.4]$ & $1.6(2)[1.4]$ & $11.3(14)$ \\
\hline 24 & $0.8(1)[-0.1]$ & 7.3 (9) [0.3] & $4.1(5)[-0.8]$ & $1.6(2)[1.1]$ & $13.8(17)$ \\
\hline 25 & $0.0(0)[-1.0]$ & $6.5(8)[0.9]$ & $2.4(3)[-1.2]$ & $1.6(2)[1.6]$ & $10.5(13)$ \\
\hline$\geq 26$ & $3.3(4)[2.9]$ & 7.3 (9) [0.1] & $4.1(5)[-1.0]$ & $0.0(0)[-1.1]$ & 14.7 (18) \\
\hline Total & $6.5(8)$ & $49.6(61)$ & $38.3(47)$ & $5.6(7)$ & 100.0 (123) \\
\hline
\end{tabular}

$P$ values with respect to that found in control patients are reported in Table 7 .

Table 6 Joint distribution of CAG and GGC percentages (number in round bracket and adjusted residuals in square bracket parenthesis) for the $105 \mathrm{TC}$ non-cryptorchid patients

\begin{tabular}{|c|c|c|c|c|c|}
\hline \multirow[b]{2}{*}{ CAG } & \multicolumn{5}{|c|}{ GGC } \\
\hline & $\leq 16$ & 17 & 18 & $\geq 19$ & Total \\
\hline$\leq 19$ & $0.9(1)[-0.1]$ & $2.9(3)[-3.3]$ & 14.2 (15) [3.6] & $0.9(1)[-0.3]$ & $18.9(20)$ \\
\hline 20 & $0.0(0)[-1.1]$ & $9.5(10)[1.2]$ & $5.7(6)[-0.1]$ & $0.0(0)[-1.1]$ & $15.2(16)$ \\
\hline 21 & $0.0(0)[-0.8]$ & $4.8(5)[0.1]$ & $4.8(5)[0.7]$ & $0.0(0)[-0.9]$ & $9.6(10)$ \\
\hline 22 & 0.9 (1) [0.7] & $4.8(5)[0.4]$ & 2.9 (3) $[-0.4]$ & $0.0(0)[-0.8]$ & $8.6(9)$ \\
\hline 23 & $0.0(0)[-0.8]$ & $4.8(5)[0.4]$ & $1.9(2)[-1.1]$ & $1.9(2)[1.9]$ & $8.6(9)$ \\
\hline 24 & 0.9 (1) [0.2] & $8.6(9)[0.9]$ & 2.9 (3) $[-1.6]$ & 1.9 (2) [1.1] & $14.3(15)$ \\
\hline 25 & $0.0(0)[-0.9]$ & $7.6(8)[1.3]$ & $1.9(2)[-1.7]$ & $1.9(2)[1.5]$ & $11.4(12)$ \\
\hline$\geq 26$ & 2.9 (3) [2.7] & $5.7(6)[-0.4]$ & $4.8(5)[-0.3]$ & $0.0(0)[-1.1]$ & $13.4(14)$ \\
\hline Total & $5.6(6)$ & $48.7(51)$ & $39.1(41)$ & $6.6(7)$ & $100.0(105)$ \\
\hline
\end{tabular}

$P$ values with respect to that found in control patients are reported in Table 7 .

residual follows a standard normal distribution, so that a value of the adjusted residual exceeding \pm 3 provides strong evidence against independence in that cell. In both TC and non-cryptorchid TC groups to the cell
$\mathrm{CAG}<19 / \mathrm{GGC}=17$ corresponds an adjusted residual smaller than -3 , providing evidence that the observed number of patients is smaller than the expected number in this cell. On the other hand, to the cell 
$\mathrm{CAG}<19 / \mathrm{GGC}=18$ corresponds an adjusted residual larger than 3, providing strong evidence that for this cell the observed number of patients is larger than the expected. The above analysis was carried out considering the three two-way tables separately. A direct comparison based on the relative risks showed that there is a difference between controls (Table 4) and TC patients (Table 5) concerning the cell $\mathrm{CAG}=20$ / $\mathrm{GGG}=17$ (prevalence of $8.1 \%$ in TC men vs $1.7 \%$ in controls, $P<0.05)$, and this difference was also present when considering patients without previous history of cryptorchidism with a prevalence of $9.5 \%$ and $P<0.01$ vs controls (Table 6). The calculated relative risks and the corresponding confidence intervals of these haplotypes are shown in Table 7 . However, no relative risk was statistically significant when the Bonferroni correction (a restrictive correction for multiple test) was applied. Furthermore, when the same analyses about different haplotypes were performed excluding non-GCTs, we had the same results both in terms of statistically significant dependence among CAG and GGC and in terms of relative risk for the haplotype CAG20/GGC17. It is noteworthy that these analyses did not show any significant dependence or relative risk when considering only non-GCTs, although the number of these cases is very small (seven patients).

Finally, in this paper we could not analyse the correlation between the presence of metastases and CAG or GGC repeat length (as reported by Giwercman et al. 2004) because our patients were all in stage I at the time of the evaluation.

\section{Discussion}

Although in the past decades much progress in TC treatment has been made, little is known about the

Table 7 Analysis of distribution of haplotypes $C A G=20$ / $\mathrm{GGC}=17$ in TC patients with and without history of cryptorchidism

\begin{tabular}{lccc}
\hline & \multicolumn{3}{c}{ CAG=20/GGC=17 } \\
\cline { 2 - 4 } & $\%$ & $\mathrm{RR}(95 \% \mathrm{Cl})$ & $P$ \\
\hline $\left.\begin{array}{l}\text { Controls }(n=115) \\
\begin{array}{l}\text { TC patients with and } \\
\text { without cryptochidism } \\
\quad(n=123)\end{array}\end{array}\right)$ & 8.1 & $4.7(1.04-20.9)$ & $<0.05$ \\
$\begin{array}{l}\text { TC patients without } \\
\text { cryptochidism } \\
(n=105)\end{array}$ & 9.5 & $5.5(1.2-24.4)$ & 0.01 \\
\hline
\end{tabular}

$\mathrm{RR}=$ relative risk, $\mathrm{Cl}=$ confidence intervals. causes of this tumour. Some authors, on the basis of genome-wide screening from a large number of families with at least two cases of TC, have suggested the presence of a testicular GCT (TGCT) susceptibility gene that might also predispose to cryptorchidism (Rapley et al. 2000). They provided evidence for a TGCT predisposition locus on chromosome Xq27 (TGCT1); however, this putative gene has yet to be identified and probably other TGCT putative genes exist. Recently, other suggestions of a genetic basis for TC (Chemes et al. 2003, Skakkebæk et al. 2003) have been made; however, specific genetic alterations including genetic susceptibility to endocrine disruption are still unknown. Although definitive proof is still lacking, it is generally assumed that the development of TC is under endocrine control (Rajpert-De Meyts et al. 1993). In particular, alterations in the pituitary-testicular hormonal axis and/or alterations in gonadotrophin and sex steroid action, are believed to be involved in the development of this tumour and in the progression from the pre-invasive carcinoma in situ stage to invasive tumour (Skakkebæk et al. 1987, Rajpert-De Meyts et al. 1993). This is supposed by clinical observations showing a main peak of TC incidence early after puberty (Prener \& Østerlind 1985). Possible hormonal candidates responsible for such tumour development are luteinizing hormone (LH), androgens and oestrogens. Probably, a combination of high LH levels, high intratesticular androgen levels coupled with lower androgen activity, and high oestradiol levels are necessary for TC development and progression. This hypothesis fits well with the observation that subjects with AIS due to mutations in the AR gene are at high risk of developing TC (Müller 1987). On the contrary, subjects with Kallmann's syndrome having hypogonadotrophic hypogonadism never develop TC. In fact, patients with AIS present high levels of androgens, LH and oestrogens together with reduced intratesticular androgen function, whereas Kallmann's patients have low levels of LH, androgens and oestradiol. Alterations in the AR gene also frequently result in other signs of the so-called TDS, such as cryptorchidism or spermatogenesis impairment. Hence, sex hormones may play a crucial role in the development of TC (Giwercman et al. 2004), thus justifying the higher risk in subjects with AIS (Savage \& Lowe 1990, Rajpert-De Meyts et al. 2000). On this basis some authors suggested a possible specific relationship between mutations in the AR gene and TC development (Sakai et al. 2000, Rajpert-De Meyts et al. 2002). Furthermore, the possible association of CAG ad GGC repeat lengths with TC has also been analysed (Rajpert-De Meyts 
et al. 2002, Giwercman et al. 2004), on the basis that expansion of these triplets caused a reduction in the functional activity of the AR. However, these two studies produced contrasting data, probably as a result of different patient selection criteria and/or differences in $\mathrm{CAG} / \mathrm{GGC}$ numbers due to ethnicity (i.e. Danish vs Sweden).

In this study, we analysed AR gene mutations and CAG and GGC triplets in a large group of Italian patients affected by TC. We found a high prevalence of AR gene mutations ( 3 out of 123, 2.4\%). One of these (P390S) was an already reported mutation (Hiort et al. 2000) found in two men affected by severe oligozoospermia. This mutation is located within a region of the AR that is important for transcriptional activity (exon 1). The importance of this amino acid residue is also highlighted by the finding of two cases of Pro390Leu affected by prostate cancer and one case of Pro390Asp affected by complete AIS (www. androgendb.mcgill.ca). The other two were novel mutations. The first was a trinucleotide deletion (CTG) in exon 1 leading to deletion of leucine in position 57 (Del L57). This amino acid is located just before the polyglutamine tract and belongs to a stretch of four leucines. The deletion of one of them may probably change the conformation of this domain, thus resulting in lower receptor activity. Supporting this hypothesis, a leucine to glutamine substitution in this codon has been associated with prostate cancer, a 30 nucleotide deletion involving this region has been associated with laryngeal cancer, and the insertion of an extra leucine at codon 58 was reported in two oligozoospermic men. The third mutation leads to an alanine to threonine substitution in amino acid 297 (A297T). Again, this mutation is located in the transactivation domain of the AR (exon 1). Even if mutations in this codon have never been reported and a direct causative effect cannot be drawn, the absence of the same mutation in more than 300 fertile control subjects evaluated for AR mutations, suggests a specific association with TC. All mutated patients had seminoma ( 3 out of $81,3.7 \%$ ) and did not have a history of cryptorchidism.

When evaluating CAG and GGC triplets we found that there is no difference with respect to control subjects when these variables are analysed separately both in GCTs and in non-GCTs. However, when joint distributions of CAG and GGC were analysed, we found significant differences. In fact, we observed that in TC subjects, differently from controls, the joint analysis of CAG and GGC showed a statistically significant dependence among these variable repeats. Furthermore, TC patients more frequently had the combination $\mathrm{CAG}=20 / \mathrm{GGC}=17$ and when subjects with a previous history of cryptorchidism were not considered the prevalence of this combination was even more evident. The same results were unchanged also when analysing GCTs alone, which are usually considered to have a natural history very different from non-GCTs. On the contrary, considering only non-GCTs the analysis of the different CAG/GGC haplotypes did not show any significant difference, but we have to consider the poor number of these patients. However, we cannot completely exclude a chance association given the high number of statistical tests necessary in these cases.

Overall, the present study reports for the first time a high prevalence of AR gene mutations in young patients affected by TC, in particular seminoma. Furthermore, we did not find differences in CAG and GGC numbers between controls and TC patients in Italy. Our data confirm the absence of an association between CAG length and TC in Sweden (Rajpert DeMeyts et al. 2002), and we have no evidence of a relationship between this triplet both vs TC histotypes (as reported by Giwercman et al. 2004) and both vs GCTs or non-GCTs. Furthermore, we agree with the latter paper that suggested no relationship between GGC triplet length and TC. Another important finding is that CAG and GGC repeats are not independent in TC patients and the haplotype $\mathrm{CAG}=20 / \mathrm{GGC}=17$ seems more frequently associated with $\mathrm{TC}$ in patients both with and without previous cryptorchidism. In fact, the relative risk results increased when considering all affected patients, and this risk is still present and seems even higher in patients without a predisposing factor for TC as cryptorchidism.

At this time, the association between CAG/GGC haplotypes and some clinical phenotypes such as infertility has been postulated (Ferlin et al. 2004a), but the mechanism by which they might cause TC are still unknown. We can suppose that different CAG/ GGC combinations may modulate AR function, and that some haplotypes could determine an alteration in the trascriptional activity of the receptor. These findings cannot be conclusive, but nonetheless agree with another report on the association of CAG and GGC length and oesophageal cancer (Dietzsch et al. 2003).

In conclusion, our data indicate a significant prevalence of AR gene mutations in TC patients and thus it is possible to hypothesize a higher risk of TC in men with AR mutations. Furthermore, this study suggests that some particular CAG and GGC haplotypes might be more frequently associated with TC. 


\section{Acknowledgements}

The financial support of the Italian Ministry of Instruction, University and Research (MIUR) is gratefully acknowledged. We declare that no author has any conflict of interest that would prejudice the impartiality of this paper.

\section{References}

Adami H, Bergström R, Möhner M, Zatonsky W, Storm H, Ekbom A, Tretli S, Teppo L, Ziegler H \& Rahu M 1994 Testicular cancer in nine northern European countries. International Journal of Cancer 59 33-38.

Agresti A \& Finlay B 1997 Statistical Methods for the Social Sciences, edn 3. Upper Saddle River, NJ: Prentice Hall.

Aitken RJ \& Sawyer D 2003 The human spermatozoon-not waving but drowning. Advances in Experimental Medicine and Biology 518 85-98.

Arai Y, Kawakita M, Okada Y \& Yoshida O 1997 Sexuality and fertility in long-term survivors of testicular cancer. Journal of Clinical Oncology 15 1444-1448.

Berthelsen JG \& Skakkebæk NE 1983 Gonadal function in men with testis cancer. Fertility and Sterility 39 68-75.

Berthelsen JG, Skakkebæk NE, von der Maase H, Sorensen BL \& Mogensen P 1982 Screening for carcinoma in situ of the contralateral testis in patients with germinal testicular cancer. British Medical Journal 285 1683-1686.

Bolsen KA, Kaleva M, Main KM, Virtanen HE, Haavisto A-M, Schmidt IM, Chellakooty M, Damgaard IN, Mau C \& Reunanen M 2004 Difference in prevalence of congenital cryptorchidism in infants between two Nordic countries. Lancet 363 1264-1269.

Bosl GJ \& Motzer RG 1997 Testicular germ-cell cancer. New England Journal of Medicine 337 242-253.

Bosl GJ, Bajorin D, Sheinfeld J \& Motzer R 1997 Cancer of the testis. In Cancer: Principles and Practice of Oncology, edn 5, pp 1397-1425. Eds VT De Vita, S Hellman \& S Rosenberg. Philadelphia, PA: JB Lippincott.

Brinkmann AO 2001 Molecular basis of androgen insensitivity. Molecular and Cellular Endocrinology 179 105-109.

Brooks BP \& Fischbeck KH 1995 Spinal and bulbar muscular atrophy: a trinucleotide-repeat expansion neurodegenerative disease. Trends in Neurosciences $\mathbf{1 8}$ 459-461.

Chamberlain NL, Driver ED \& Miesfeld RL 1994 The length and location of CAG trinucleotide repeats in the androgen receptor $\mathrm{N}$-terminal domain affect transactivation function. Nucleic Acids Research 22 3181-3186.

Chemes HE, Muzulin PM, Venara MC, del Caren Muhlman M, Martinez M \& Gamboni M 2003 Early manifestations of testicular dysgenesis in children: pathological phenotypes, karyotype correlations and precursor stages of tumour development. Acta Pathologica, Microbiologica et Immunologica Scandinavica 111 12-24.

Chilvers C, Dudley NE, Gough MH, Jackson MB \& Pike MC 1986 Undescended testis: the effect of treatment on subsequent risk of subfertility and malignancy. Journal of Pediatric Surgery 21 691-696.

Choong CS, Kemppainen JA, Zhou ZX \& Wilson EM 1996 Reduced androgen receptor gene expression with first exon CAG repeat expansion. Molecular Endocrinology 10 1527-1535.

Devesa SS, Blot WJ, Stone BJ, Miller BA, Tarone RE \& Fraumeni JFJ 1995 Recent cancer trends in the United States. Journal of the National Cancer Institute $\mathbf{8 7}$ 175-182.

Dietsch E, Laubsher R \& Parker MI 2003 Esophageal cancer risk in relation to GGC and CAG trinucleotide repeat lengths in the androgen receptor gene. International Journal of Cancer 107 38-45.

Ding D, Xu L, Menon M, Reddy GP \& Barrack ER 2004 Effect of GGC (glycine) repeat length polymorphism in the human androgen receptor on androgen action. Prostate 62 133-139.

Farrer JH, Walker AH \& Rajfer J 1985 Management of the postpuberal cryptorchid testis: a statistical review. Journal of Urology 134 1071-1076.

Ferlin A, Moro E, Rossi A, Dalla Piccola B \& Foresta C 2003 The human Y chromosome's azoospermia factor $\mathrm{b}$ $(\mathrm{AZFb})$ region: sequence, structure, and deletion analysis in infertile men. Journal of Medical Genetics 40 18-24.

Ferlin A, Bartoloni L, Rizzo G, Roverato A, Garolla A \& Foresta C 2004a Androgen receptor gene CAG and GGC repeat lengths in idiopathic male infertility. Molecular Human Reproduction 10 417-421.

Ferlin A, Bettella A, Tessari A, Salata E, Dallapiccola B \& Foresta C 2004b Analysis of the DAZ gene family in cryptorchidism and idiopathic male infertility. Fertility and Sterility 81 1013-1018.

Foresta C, Ferlin A, Garolla A, Rossato M, Barbaux S \& De Bortoli A 1997 Y-chromosome deletions in idiopathic severe testiculopathies. Journal of Clinical Endocrinology and Metabolism 82 1075-1080.

Giovannucci E, Stampfer MJ, Krithivas K, Brown M, Dahl D, Brufsky A, Talcott J, Hennekens CH \& Kantoff PW 1997 The CAG repeat within the androgen receptor gene and its relationship to prostate cancer. PNAS 94 3320-3323.

Giwercman A 1992 Carcinoma-in-situ of the testis: screening and management. Scandinavian Journal of Urology and Nephrology. Supplementum 148 1-47.

Giwercman A, Brunn E, Frimodt-Møller C \& Skakkebæk NE 1989 Prevalence of carcinoma in situ and other histopathological abnormalities in testes of men with a history of cryptorchidism. Journal of Urology 142 998-1002.

Giwercman A, Lundin KB, Eberhard J, Stahl O, Cwikiel M, Cavallin-Stahl E \& Giwercman YL 2004 Linkage between androgen receptor gene CAG trinucleotide repeat length 
and testicular germ cell cancer histological type and clinical stage. European Journal of Cancer 40 2152-2158.

Guo YL, Hsu PC, Hsu CC \& Lambert GH 2000 Semen quality after prenatal exposure to polychlorinated biphenyls and dibenzofurans. Lancet 356 1240-1241.

Hakimi JM, Shoenberg MP, Rondinelli RH, Piantadosi S \& Barrack ER 1997 Androgen receptor variants with short glutamine or glycine repeats may identify unique subpopulations of men with prostate cancer. Clinical Cancer Research 3 1599-1608.

Hemminki K \& Li X 2004 Familial risk in testicular cancer as a clue to heritable and environmental aetiology. British Journal of Cancer 90 1765-1770.

Herr HW, Bar-Chama N, O’Sullivan M \& Sogani PC 1998 Paternity in men with stage I tumours on surveillance. Journal of Clinical Oncology 16 733-734.

Hiort O, Holterhus PM, Horter T, Schulze W, Kremke B, Bals-Pratsch M, Sinnecker GHG \& Kreuse K 2000 Significance of mutations in the androgen receptor gene in males with idiopathic infertility. Journal of Clinical Endocrinology and Metabolism 85 2810-2815.

Hsing AW, Gao YT, Wu G, Wang X, Deng J, Chen YL, Sesterhenn IA, Mostofi FK, Benichou J \& Chang C 2000 Polymorphic CAG and GGN repeat lengths in the androgen receptor gene and prostate cancer risk: a population-based case-control study in China. Cancer Research 60 5111-5116.

Huyge T, Matsuda T \& Thonneau P 2003 Increasing incidence of testicular cancer worldwide: a review. Journal of Urology 170 5-11.

Huyge E, Matsuda T, Daudin M, Chevreau C, Bachaud JM, Plante P, Bujan L \& Thonneau P 2004 Fertility after testicular cancer treatments: results of a large multicenter study. Cancer 15 732-737.

Ingles SA, Ross RK, Yu MC, Irvine RA, La Pera G, Haile RW \& Coetzee GA 1997 Association of prostate cancer risk with genetic polymorphisms in vitamin D receptor and androgen receptor. Journal of the National Cancer Institute 89 166-170.

Irvine RA, Yu MC, Ross RK \& Coetzee GA 1994 The CAG and GGC microsatellites of the androgen receptor gene are in linkage disequilibrium in men with prostate cancer. Cancer Research 54 2861-2864.

Jacobsen R, Bostofte E, Engholm G, Hansen J, Skakkebæk NE \& Møller H 2000 Fertility and offspring sex ratio of men who develop testicular cancer: a record linkage study. Human Reproduction 15 1958-1961.

Kantoff P, Giovannucci E \& Brown M 1998 The androgen receptor CAG repeat polymorphism and its relationship to prostate cancer. Biochimica et Biophysica Acta $\mathbf{1 3 7 8}$ C1-C5.

Kazemi-Esfarjani P, Trifiro MA \& Pinsky L 1995 Evidence for a repressive function of the long polyglutamine tract in the human androgen receptor: possible pathogenetic relevance for the (CAG)nexpanded neuronopathies. Human Molecular Genetics 4 523-527.
Kittles RA, Young D, Weinrich S, Hudson J, Argyropoulos G, Ukali F, Adams-Campbell L \& Dunston GM 2001 Extent of linkage disequilibrium between the androgen receptor gene CAG and GGC repeats in human populations: implications for prostate cancer risk. Human Genetics 109 253-261.

Lubahn DB, Brown TR, Simental JA, Higgs HN, Migeon CJ, Wilson EM \& French FS 1989 Sequence of the intron/ exon junctions of the coding region of the human androgen receptor gene and identification of a point mutation in a family with complete androgen insensitivity. PNAS 86 9534-9538.

Lundin KB, Giwercman A, Richthoff J, Abrahamsson PA \& Giwercman YL 2003 No association between mutations in the human androgen receptor GGN repeat ad inter-sex conditions. Molecular Human Reproduction 9 375-379.

Møller H 1993 Clues to the aetiology of testicular germ cell tumours from descriptive epidemiology. European Urology 23 8-13.

Møller H \& Skakkebæk NE 1999 Risk of testicular cancer in subfertile men: case-control study. British Medical Journal 318 559-562.

Müller J 1987 Abnormal infantile germ cells and development of carcinoma-in situ in maldeveloped testes: a stereological and densitometric study. International Journal of Andrology 10 543-567.

Patel MI, Motzer RJ \& Sheinfeld J 2003 Management of recurrence and follow-up strategies for patients with seminoma and selected high-risk groups. Urologic Clinics of North America 30 803-817.

Platz EA, Giovannucci E, Dahl DM, Krithivas K, Hennekens CH, Brown M, Stampfer MJ \& Kantoff PW 1998 The androgen receptor gene GGN microsatellite and prostate cancer risk. Cancer Epidemiology, Biomarkers and Prevention 7 379-384.

Pottern LM, Brown LM, Hoover RN, Javadpour N, O'Connell KJ, Stutzman RE \& Blattner WA 1985 Testicular cancer risk among young men: role of cryptorchidism and inguinal hernia. Journal of the National Cancer Institute 148 1-47.

Prener A \& Østerlind A 1985 Cancer in Denmark. Copenhagen: Danish Cancer Registry.

Prener A, Engholm G \& Jensen OM 1996 Genital anomalies and risk for testicular cancer in Danish men. Epidemiology 7 14-19.

Rajpert-De Meyts E \& Skakkebæk NE 1993 The possible role of sex hormones in the development of testicular cancer. European Urology 23 54-61.

Rajpert-De Meyts E, Toppari J \& Skakkebæk NE 2000 Testicular tumours with endocrine manifestations. In Endocrinology, edn 4, chapter 175. Eds LJ De Groot \& JL Jameson. Philadelphia, PA: Saunders.

Rajpert-De Meyts E, Leffer H, Daugaard G, Andersen CB, Petersen PM, Hinrichsen J, Pedersen LG \& Skakkebæk NE 2002 Analysis of the polymorphic CAG repeat length in the androgen receptor gene in patients with testicular 
germ cell cancer. International Journal of Cancer 102 201-204.

Rapley EA, Crockford GP, Teare D, Biggs P, Seal S, Barfoot R, Edwards S, Hamoudi R, Heimdal K \& Fossa SD 2000 Localization of Xq27 of a susceptibility gene for testicular germ-cell tumours. Nature Genetics $\mathbf{2 4}$ 197-200.

Rørth M, Rajpert-De Meyts E, Andersson L, Dickerman KP, Fossa SD, Grigor KM, Hendry WF, Herr HW, Looijenga LH \& Oosterhuis JW 2000 Carcinoma in situ in the testis. Scandinavian Journal of Urology and Nephrology. Supplementum 205 166-186.

Sakai N, Yamada T, Asao T, Baba M, Yoshida M \& Murayama T 2000 Bilateral testicular tumours in androgen insensitivity syndrome. International Journal of Urology 7 390-392.

Savage MO \& Lowe DG 1990 Gonadal neoplasia and abnormal sexual differentiation. Clinical Endocrinology 32 519-533.

Sharpe RM \& Skakkebæk NE 1993 Are oestrogens involved in falling sperm counts and disorders of male reproductive tract? Lancet 341 1392-1395.

Shottenfeld D, Warshauer ME, Sherlock S, Zauber AG, Leder M \& Payne R 1980 The epidemiology of testicular cancer in young adults. American Journal of Epidemiology 112 232-246.

Skakkebæk NE, Berthelsen JG, Giwercman A \& Müller J 1987 Carcinoma-in situ of the testis: possible origin from gonocytes and precursor of all types of germ cell tumours except spermatocytoma. International Journal of Andrology 10 19-28.

Skakkebæk NE, Rajpert-De Meyts E \& Main KM 2001 Testicular dysgenesis syndrome: an increasingly common developmental disorder with environmental aspects. Human Reproduction 16 972-978.
Skakkebæk NE, Holm M, Hoei-Hansen C, Jørgensen N \& Rajpert-De Meyts E 2003 Association between testicular dysgenesis syndrome (TDS) and testicular neoplasia: Evidence from 20 adult patients with signs of maldevelopment of the testis. Acta Pathologica, Microbiologica, et Immunologica Scandinavica 111 1-11.

Staden R 1996 The Staden sequence analysis package. Molecular Biotechnologies 5 233-241.

Stanford JL, Just JJ, Gibbs M, Wicklund KG, Neal CL, Blumenstein BA \& Ostrander EA 1997 Polymorphic repeat in the androgen receptor gene: molecular markers of prostate cancer risk. Cancer Research 57 1194-1198.

Sultan C, Paris F, Terouanne B, Balaguer P, Georget V, Poujol N, Jeandel C, Lumbroso S \& Nicolas JC 2001 Disorders linked to insufficient androgen action in male children. Human Reproduction Update 7 314-322.

Toppari J \& Skakkebæk NE 1998 Sexual differentiation and environmental endocrine disrupters. Baillieres Clinical Endocrinology and Metabolism 12 143-156.

Toppari J, Haavisto A-M \& Alanen M 2002 Changes in male reproductive health and effects of endocrine disruptors in Scandinavian countries. Cadernos de Saude Publica 18 413-420.

Weir HK, Marrett LD, Kreiger N, Darlington GA \& Sugar L 2000 Pre-natal and peri-natal exposures and risk of testicular germ cell cancer. International Journal of Cancer $87438-443$.

Whitaker RH 1988 Neoplasia in cryptorchid men. Seminars in Urology 6 107-109.

World Health Organization 1999 Laboratory Manual for the Examination of Human Semen and Sperm-Cervical Mucus Interaction. Cambridge: Cambridge University Press.

Yasuda Y, Kihaja T \& Taniura T 1985 Effect of ethinyl estradiol on the differentiation of mouse foetal testis. Teratology 32 113-118. 
